\title{
Sex-Gender Differences in Diabetic Retinopathy
}

\author{
Sara Cherchi ${ }^{1, *}$, Alfonso Gigante ${ }^{2}$, Maria Anna Spanu ${ }^{3}$, Pierpaolo Contini ${ }^{4}$, Gisella Meloni ${ }^{5}$, \\ Maria Antonietta Fois ${ }^{6}$, Danila Pistis ${ }^{2}$, Rosangela M. Pilosu ${ }^{4}$, Alessio Lai ${ }^{7}$, Salvatore Ruiu ${ }^{8}$, \\ Ilaria Campesi ${ }^{9}$ (i) and Giancarlo Tonolo ${ }^{1, *}$ \\ 1 SC Diabetologia Aziendale ASSL Olbia, 07026 Olbia, Italy \\ 2 Diabetologia ASSL Nuoro, 08100 Nuoro, Italy; alfonso.gigante@atssardegna.it (A.G.); \\ danila.pistis@atssardegna.it (D.P.) \\ 3 Diabetologia ASSL Sassari, 07100 Sassari, Italy; mariaanna.spanu@atssardegna.it \\ 4 Diabetologia San Giovanni di Dio AOU Cagliari, 09121 Cagliari, Italy; pierpaolocontini@aouca.it (P.C.); \\ rosangelamaria.pilosu@atssardegna.it (R.M.P.) \\ 5 Diabetologia ASSL Lanusei, 08045 Lanusei, Italy; gisella.meloni@atssardegna.it \\ Diabetologia Isili ASSL Cagliari, 09121 Cagliari, Italy; mariaantonietta.fois@atssardegna.it \\ Diabetologia Senorbì ASSL Cagliari, 09121 Cagliari, Italy; alessio.lai@atssardegna.it \\ Poliambulatorio Oculistica ASSL Olbia, 07026 Olbia, Italy; distretto.olbia@atssardegna.it \\ Department Scienze Biomediche, Università degli Studi di Sassari, 07100 Sassari, Italy; \\ ilacampesi79@yahoo.it \\ * Correspondence: cherchisara@yahoo.it (S.C.); giancarlo.tonolo@atssardegna.it (G.T.)
}

Received: 30 January 2020; Accepted: 14 April 2020; Published: 20 April 2020

\begin{abstract}
Diabetic retinopathy (DR) is one of the main causes of visual loss in individuals aged 20-64 years old. The aim of this study was to investigate, in a multicenter retrospective cross-sectional study, sex-gender difference in DR in a large sample of type 2 diabetic patients (T2DM). 20,611 T2DM regularly attending the units for the last three years were classified as having: (a) No DR (NDR), (b) nonproliferative DR (NPDR), or (c) preproliferative/proliferative DR (PPDR). DR of all grades was present in $4294 \mathrm{~T} 2 \mathrm{DM}(20.8 \%)$, with a significant higher prevalence in men as compared to women (22.0\% vs. $19.3 \% p<0.0001)$. Among DR patients, both NPDR and PPDR were significantly more prevalent in men vs. women ( $p=0.001$ and $p=0.0016$, respectively). Women had similar age and BMI, but longer diabetes duration, worse glycemic metabolic control, and more prevalence of hypertension and chronic renal failure (CRF) of any grade vs. men. No significant differences between sexes were evident in term of drug therapy for diabetes and associate pathologies. Conclusions: In this large sample of T2DM, men show higher prevalence of DR vs. women, in spite of less represented risk factors, suggesting that male sex per se might be a risk factor for DR development.
\end{abstract}

Keywords: diabetes complications; type 2 diabetes; microvascular complications

\section{Introduction}

Diabetic retinopathy (DR) is one of the main causes of visual loss in diabetic subjects of age between 20 and 64 years [1]. Diabetic retinopathy can be classified as nonproliferative (NPDR), usually mild where the walls of the blood vessels in the retina weaken with tiny bulges (microaneurysms) protruding from the vessel walls of the smaller vessels, sometimes leaking fluid and blood into the retina far away from the macula. NPDR can progress to a more severe type, sometimes termed preproliferative, characterized by leaking fluid and/or blood closely to the macula, which is a prelude to the more advanced form of proliferative diabetic retinopathy. In proliferative diabetic retinopathy, damaged blood vessels close off, causing the growth of new, abnormal blood vessels in the retina, and can leak into the clear vitreous, possibly ending in visual loss [1]. 
Careful control of glycaemia and blood pressure can reduce the risk of developing DR and delay its progression [2]. Higher HBA1c level, diabetes duration, hypertension, and chronic renal failure are globally recognized risk factors for the development of DR [3-6].

Differences between men and women, both in type 1 and type 2 diabetes incidence and in the development of chronic complications, have been reported by several epidemiological studies [7-9]. Controversial results are available in the literature regarding DR and sex-gender differences. Some studies report a higher risk of DR among men [10-14], while others suggest that women might have a higher prevalence of DR than men [15-17]. A clinic-based retrospective longitudinal study with Japanese type 2 diabetes mellitus patients indicated female sex as an independent risk factor for the development of DR, with female sex showing higher prevalence of proliferative DR at baseline [18]. Only a few old reports do not show significant gender difference [19]. Moreover, DR progresses during pregnancy [20,21], suggesting a possible role of sex hormones in retinal damage in diabetes [22,23]. The controversial results on gender differences in DR might be related to ethnic differences, population selection with sometimes mixed T1DM and T2DM subjects or otherwise not well specified, low numbers of observations, and differences in drug treatment for diabetes or associated pathologies between sexes.

As new therapies for diabetic retinopathy are available (from laser-based therapies to vitrectomy and intravitreal corticosteroids, antivascular endothelial growth factors, and more advanced stem cells and ribonucleic acid interference technologies), it becomes demanding to evaluate all the risk factors of DR onset from a gender perspective. Gender is generally considered a social construct that manifests as female in women and male in men, whereas sex is considered the biological aspect of femininity and masculinity. Sex and gender have numerous interactions [24], and sometimes it is difficult to divide sex from gender; thus, it is preferable to adopt "sex-gender" terminology that strongly suggests that the two concepts are jointed. Differences and inequalities in health status often derive from both biological differences and social, cultural, and political arrangements in society. Therefore, we will use this term through this paper.

The aim of this study was to investigate possible sex-gender differences in DR in a large cohort of Sardinian type 2 diabetes (T2DM) patients in a retrospective cross-sectional study.

\section{Methods}

A multicenter observational retrospective cross-sectional study was carried out on T2DM patients from seven diabetes care units located in different areas of Sardinia: Olbia (OT), Sassari (SS), Nuoro (NU), Lanusei (LA), Isili (IS), Cagliari (CA), and Selargius (SE).

The study was approved by the "Comitato di Bioetica" ATS Sardegna on 27 Jan 2015.

We selected patients with established diagnosis of T2DM regularly attending the Unit from more than three years with at least two coincident eye examination in the period 2016-2018. Diagnosis of type 2 diabetes was done according to the presence of fasting blood glucose more than $126 \mathrm{mg} / \mathrm{dL}$, glycated hemoglobin more than $6.5 \%$, or blood glucose more than $200 \mathrm{mg} / \mathrm{dL}$ at $120^{\prime}$ of an $75 \mathrm{~g}$ Oral Glucose Tolerance test or blood glucose more than $200 \mathrm{mg} / \mathrm{dL}$ at any time with symptoms. Out of a total of 29,785 T2DM (16,852 men and 12,933 women), 8242 did not fulfill the enrolment criteria (T2DM diagnosis criteria, irregular attendance to the operative Unit, no coincident eye examination in the period 2016-2018 available) and were excluded. From the remaining 21,543 T2DM patients (12,154 men and 9389 women) enrolled, 932 had maculopathy, and in the remaining 20,611 patients, the prevalence of DR of any grade was $20.8 \%$.

These 20,611 T2DM subjects were divided in two sets: Set 1: patients with HbA1c aggregation data and eye examination (13,267: 7704 men and 5564 women) these patients were enrolled in the OT, SS, and NU diabetes care units; Set 2: patients with only eye examination (7344: 3969 men and 3375 women) these patients were enrolled in the LA, IS, SE, and CA diabetes care units. Set 2 was selected to confirm/deny the results of a different rate of DR between men and women, which was eventually found in set one. 
In addition, full clinical data extracted from the clinical database of the Olbia operative unit (OT) were available for 5362 T2DM patients (3003 men and 2359 women). HbA1c, body mass index (BMI), creatinine, urinary albumin excretion rate, total and HDL cholesterol, and triglycerides (TG) were extrapolated from the database, and the mean of the data for any single patient in the last available year was used. Estimated glomerular filtration fraction (eGFR) was calculated with the MDRD equation [25], LDL cholesterol was calculated with the Friedewal formula [(total cholesterol-HDL-Cholesterol)/triglycerides]. Chronic renal failure of any grade was defined from eGFR $<60 \mathrm{~mL} / \mathrm{min} / \mathrm{m}^{2}$ in two consecutive occasions at least one month apart, and hypertension as blood pressure $>140 / 90 \mathrm{mmHg}$ in three different occasions or antihypertensive drug use.

DR was classified after full midriatic eye observation by an ophthalmologists as: (a) no signs of DR (NDR), (b) nonproliferative mild to moderate DR (NPDR), (c) preproliferative/proliferative DR (PPDR), and (d) maculopathy (MAC) [26].

The primary endpoint was the evaluation of sex-gender differences in the different grades of DR, while secondary endpoints included the association between DR and clinical and biochemical parameters in T2DM men and women as well as the sex-gender differences in DR associated diseases and therapies.

Numerical variables were represented as mean \pm standard deviation (SD), and categorical variables were presented as frequencies and percentages. Bivariate analysis was performed using Student's $t$-test for continuous variables and $\mathrm{chi}^{2}$ test for categorical variables. Statistical significance was set at $5 \%$ level. A $p$-value of $<0.05$ was deemed statistically significant.

Logistic regression analysis was performed in the 5362 T2DM patients of the Olbia Unit to identify independent risk factors for diabetic retinopathy using sex as categorical variable and blood pressure, diabetes duration, triglycerides, and $\mathrm{HbA} 1 \mathrm{c}$ as continuous variables.

\section{Results}

All selected patients attended the outpatient clinics regularly without significant differences between males and females. For the flow chart of the study see supplementary material (Figure S1). Nine hundred thirty-two T2DM patients had maculopathy (MAC: 481 men and 451 women) with no significant sex-gender differences. In set 1 (7704 men and 5563 women), DR of any grade was significantly more represented in men (NPDR $16.5 \%$ vs. $14.6 \% p=0.0017$ and PPDR $6.5 \%$ vs. $5.5 \%$ $p=0.01$ ), indicating that men having more DR than women (Figure 1).

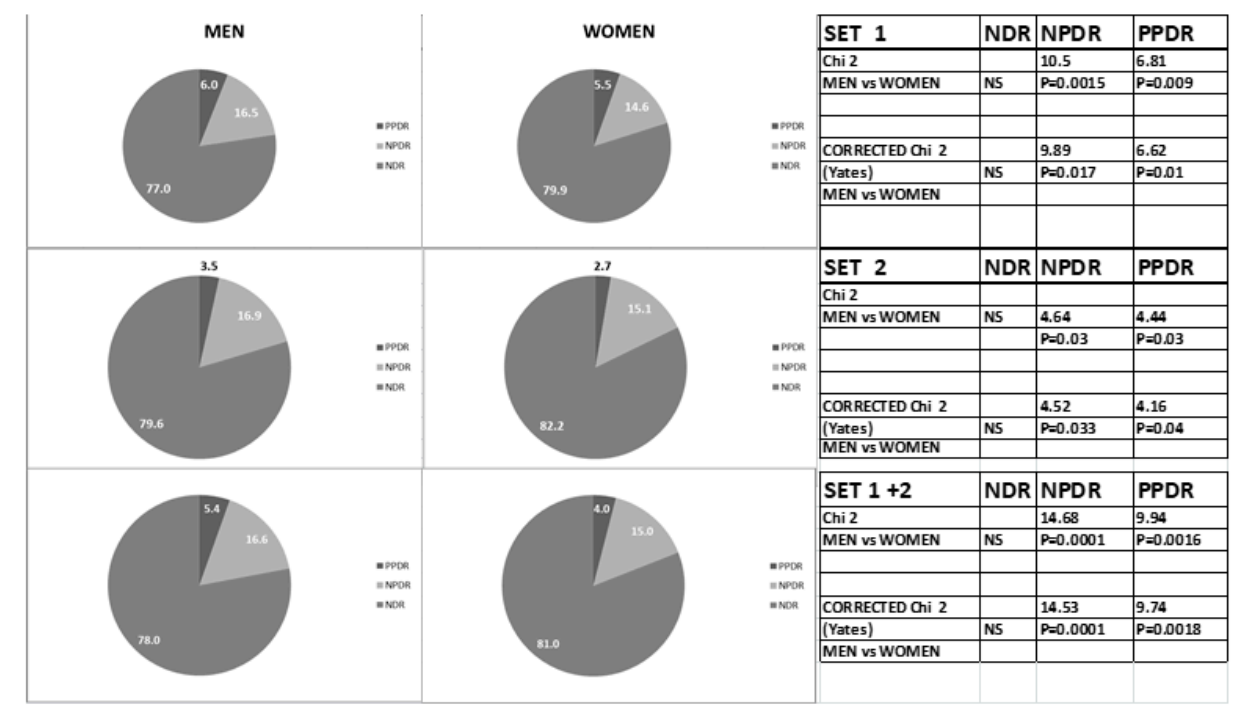

Figure 1. Percentage of diabetic retinopathy (DR) in T2DM patients divided for sex and DR grade [No DR (NDR); Non proliferative DR (NPDR), and pre-proliferative/proliferative DR (PPDR)] in set 1, set 2 and in Set 1+2, respectively. Tables represents the results of Chi 2 analysis. 
This data was confirmed in the independent analysis performed in set 2 ( 3969 men and 3375 women) with a significant prevalence of DR in men (NPDR $16.9 \%$ vs. $15.1 \% p=0.03$ and PPDR 3.5\% vs. $2.7 \%$ $p=0.04$, Figure 1). When data from set one and two were joined (11,673 men and 8938 women), men confirmed having a significantly higher rate of DR of any grade $(p<0.0001)$ and individually for NPDR $(p=0.001)$ and PPDR $p=0.0018)$ in comparison to women (Figure 1). Since premenopausal women represented $2.6 \%$ of the women sample (144/5563 in set 1 and 81/3375 in set 2), no attempt to stratify women in pre/postmenopausal status was made.

Table 1 reports data for T2DM patients of set 1 divided by DR class and $\mathrm{HbA} 1 \mathrm{c} \leq 7 \%,>7 \%$ or $>8 \%$ : women consistently showed higher prevalence of subjects in all classes of DR, with HbA1c over $7 \%$ or over $8 \%$ being significantly in the NPDR group, indicating generally worse metabolic control in the women group.

Table 1. Diabetic retinopathy grade and $\mathrm{HbA} 1 \mathrm{c} \leq 7 \%,>7 \%$, or $\mathrm{HbA} 1 \mathrm{c}>8 \%$ of T2DM patients of set 1 (Olbia (OT), Sassari (SS), Nuoro (NU) = 13,267 T2DM) divided by sex (MEN, WOMEN).

\begin{tabular}{cccccc}
\hline & Number & SEX & HbA1c $\leq \mathbf{7 \%}$ & HbA1c $>$ 7\% & HbA1c > 8\% \\
\hline \multirow{2}{*}{ NRD } & 5936 & MEN & $51.9 \%$ & $48.1 \%$ & $14.0 \%$ \\
& 4443 & WOMEN & $48.8 \%$ & $51.2 \%$ & $14.8 \%$ \\
NPDR & 1269 & MEN & $42.0 \%$ & $58.0 \% *$ & $18.8 \% \%^{* *}$ \\
& 813 & WOMEN & $33.9 \%$ & $66.1 \% *$ & $25.2 \%$ \\
\multirow{2}{*}{ PPDR } & 499 & MEN & $27.9 \%$ & $72.1 \%$ & $29.1 \%$ \\
& 307 & WOMEN & $25.4 \%$ & $74.6 \%$ & $29.4 \%$ \\
\hline
\end{tabular}

Chi $2 * p=0.006 * * p=0.007$, Corrected Chi2 $=\left(\right.$ Yates ${ }^{*} p=0.0000,{ }^{* *} p=0.0001$. No diabetic retinopathy (NDR) Nonproliferative diabetic retinopathy (NPDR), preproliferative/proliferative diabetic retinopathy (PPDR). Data are reported as \%.

Clinical data were available for T2DM patients of OT unit (5362 T2DM patients: men 3003 and women 2359). In this additional subset, men showed higher prevalence of DR as compared to women (NPDR $p=0.041$, PPDR $p=0.033$ ). In these patients, subjects with NPDR and PPDR were older, showed a longer diabetes duration, worse metabolic control, and lower eGFR in comparison to NDR (Table 2).

Table 2. Data from the 5362 T2DM (WOMEN 2359, MEN 3003) of the Olbia operative Unit: Distribution of diabetic retinopathy and clinical parameters divided by sex (MEN, WOMEN) and diabetic retinopathy grade.

\begin{tabular}{|c|c|c|c|c|}
\hline & & NDR & NPDR & PPDR \\
\hline \multirow{2}{*}{ Age (years) } & MEN & $68.1 \pm 8.6$ & $74.0 \pm 10.2 \overline{\mathrm{T}}$ & $73.1 \pm 8.0 \overline{\mathrm{T}}$ \\
\hline & WOMEN & $68.8 \pm 9.0$ & 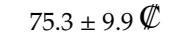 & $73.0 \pm 8.1 \not \mathbb{C}$ \\
\hline \multirow{2}{*}{ DD (years) } & MEN & $10.1 \pm 5.4$ & $17.0 \pm 9.9 \overline{\mathrm{T}} . * * *$ & $21 \pm 10 \overline{\mathrm{T}}$ \\
\hline & WOMEN & $10.4 \pm 5.4$ & $20.3 \pm 10.7 \not C$ & $22 \pm 10 \not ̋$ \\
\hline \multirow{2}{*}{ BMI (kg/m2) } & MEN & $29.4 \pm 3.7$ & $29.0 \pm 6$ & $30.0 \pm 5.2$ \\
\hline & WOMEN & $29.8 \pm 4.7$ & $31.1 \pm 12$ & $31.4 \pm 6.8$ \\
\hline \multirow{2}{*}{ HbA1c (\%) } & MEN & $6.8 \pm 0.9 *$ & $7.3 \pm 1.4 \overline{\mathrm{T}} . *$ & $7.8 \pm 1.1 \overline{\mathrm{T}}$. * \\
\hline & WOMEN & $7.0 \pm 0.9$ & $7.5 \pm 1.3 \not ̋$ & $8.3 \pm 1.7 \not{\mathbb{C}}$ \\
\hline \multirow{2}{*}{ Total cholesterol (mg/dL) } & MEN & $162 \pm 27^{* * *}$ & $163 \pm 35$ & $156 \pm 38$ \\
\hline & WOMEN & $174 \pm 27$ & $168 \pm 39$ & $160 \pm 39$ \\
\hline \multirow{2}{*}{ HDL (mg/dL) } & MEN & $44 \pm 9^{* * *}$ & $45 \pm 12^{* * *}$ & $42 \pm 9.9^{* *}$ \\
\hline & WOMEN & $51 \pm 10$ & $51 \pm 16$ & $49 \pm 13$ \\
\hline \multirow{2}{*}{ LDL (mg/dL) } & MEN & $115 \pm 62$ & $96 \pm 46^{* * *}$ & $100 \pm 50$ \\
\hline & WOMEN & $114 \pm 4$ & $110 \pm 66$ & $118 \pm 42$ \\
\hline \multirow{2}{*}{ TG (mg/dL) } & MEN & $105 \pm 32^{* * *}$ & $116 \pm 31$ & $90 \pm 28$ \\
\hline & WOMEN & $104 \pm 31$ & $116 \pm 30$ & $92 \pm 38$ \\
\hline \multirow{2}{*}{ Creatinine $(\mu \mathrm{mol} / \mathrm{L})$} & MEN & $88.0 \pm 32.4^{* * *}$ & $96.0 \pm 46^{* * *}$ & $103.5 \pm 44.9$ \\
\hline & WOMEN & $74.0 \pm 31.0$ & $82.8 \pm 44.1 \mathbb{C}$ & $91.8 \pm 66.7 \mathbb{C}$ \\
\hline \multirow{2}{*}{ AER $(\mathrm{mg} / \mathrm{L})$} & MEN & $32 \pm 108^{* * *}$ & $56 \pm 159 \overline{\mathrm{T}} . * * *$ & $85 \pm 178$ T . * \\
\hline & WOMEN & $26 \pm 94$ & $16 \pm 45$ & $45 \pm 112$ \\
\hline \multirow{2}{*}{ eGFR (mL/min/m2) } & MEN & $77 \pm 29$ & $67 \pm 39$ & $62 \pm 38 \overline{\mathrm{T}}$ \\
\hline & WOMEN & $71 \pm 26$ & $60 \pm 35$ & $54 \pm 42 \mathbb{C}$ \\
\hline
\end{tabular}

No diabetic retinopathy (NDR) Nonproliferative diabetic retinopathy (NPDR), preproliferative/proliferative diabetic retinopathy (PPDR). MEN vs. WOMEN $={ }^{*} p<0.05,{ }^{* *} p<0.01,{ }^{* * *} p<0.001$; Within MEN vs. NDR $=\mathbf{T} p<0.001$; Within WOMEN vs. NDR $=\mathbb{C}_{p}<0.01, \not{C} p<0.001$ 
Women showed significantly higher values, in comparison with men, for diabetes duration ( $p<0.001$ in NPDR), HbA1c ( $p<0.05$ in all classes), HDL-cholesterol $(p<0.01$ in all classes) and LDL-cholesterol ( $p<0.001$ in NPDR), while BMI, total cholesterol, and TG were similar in men and women in the different groups without significant differences. Creatinine was higher in men, but no differences in calculated eGFR was evident between men and women. In the different classes (NDR, NPDR and PPDR), in both sexes, eGFR decreased constantly while diabetes duration and age increased, again without significant differences between men and women. Albumin excretion rate (AER) was somehow significantly higher in men in all groups.

Finally, associated pathologies were analyzed for T2DM patients of OT unit (Table 3).

Table 3. Data for associated pathologies: Hypertension (HT) and chronic renal failure any grade (CKF) in the 5362 T2DM of the Olbia operative Unit. Distribution of diabetic retinopathy and clinical parameters divided for sex (MEN, WOMEN) and diabetic retinopathy grade.

\begin{tabular}{ccccccc}
\hline & \multicolumn{2}{c}{$\begin{array}{c}\text { NDR } \\
\text { MEN = 2331 } \\
\text { WOMEN }=\mathbf{1 9 1 2}\end{array}$} & \multicolumn{2}{c}{$\begin{array}{c}\text { NPDR } \\
\text { MEN = 504 } \\
\text { WOMEN }=344\end{array}$} & \multicolumn{2}{c}{$\begin{array}{c}\text { PPDR } \\
\text { MEN = 168 } \\
\text { WOMEN = 103 }\end{array}$} \\
\hline & HT & CKF & HT & CKF & HT & CKF \\
\hline MEN \% & 20.3 & 6.1 & 30.3 & 6.6 & 14.8 & 11 \\
WOMEN \% & 27.3 & 4.7 & 33.7 & 8.9 & 20.1 & 22.5 \\
Chi2 & $p=0.0000$ & $p=0.002$ & $\mathrm{~ns}$ & $\mathrm{~ns}$ & $\mathrm{~ns}$ & $p=0.0000$ \\
Corrected Chi2 & $p=0.0000$ & $p=0.002$ & $\mathrm{~ns}$ & $\mathrm{~ns}$ & $\mathrm{~ns}$ & $p=0.0000$ \\
\hline
\end{tabular}

No diabetic retinopathy (NDR) Nonproliferative diabetic retinopathy (NPDR), preproliferative and proliferative diabetic retinopathy (PPDR). Results are given as $\%$ of subjects.

Women had more hypertension in all DR classes, being significant in NDR and PPDR. Chronic renal failure (CRF) had a higher prevalence in NDR men in comparison with NDR women, while it was significantly higher in PPDR women than in PPDR men.

No significant difference between men and women were present in drug therapy for diabetes or for antihypertensive drugs or lipid lowering drug use. Among antihypertensive drugs, no significant differences in Angiotensin Converting Enzyme Inhibitors (ACEI) or Angiotensin II Receptor Blockers (ARB) use was present between men and women as well as in the use of statins (Table 4).

Table 4. Drug therapy for diabetes and associated pathologies in the 5362 T2DM patients of Olbia operative unit divided for sex (MEN, WOMEN) and diabetic retinopathy grade.

\begin{tabular}{ccc}
\hline SEX & MEN & WOMEN \\
\hline N $(\%)$ & $3003(56)$ & $2359(44)$ \\
\hline DIABETES THERAPY (\%) & & \\
\hline DIET & 6.5 & 5.8 \\
DIET/OHA & 61.9 & 59.3 \\
OHA + I & 12.7 & 15.2 \\
I & 18.9 & 19.7 \\
\hline OTHER DRUG THERAPY \% & & \\
\hline ANTI HYPERTENSIVE & 62 & 59 \\
ACEI/ARB USE & 51.8 & 52.2 \\
LIPID LOWERING & 48 & 48 \\
STATIN USE & 94.1 & 92.5 \\
\hline
\end{tabular}

No diabetic retinopathy (NDR) Nonproliferative diabetic retinopathy (NPDR), preproliferative/proliferative diabetic retinopathy (PPDR). OHA = Oral Antidiabetic Drugs, OHA + I = Oral Antidiabetic Drugs + Insulin, I = Insulin, $\mathrm{ACEI} / \mathrm{ARB}=$ Converting Enzyme Inhibitors/Angiotensin Receptor Blockers. Data are reported as \%. No significant differences between Men and Women.

The logistic regression analysis performed in the Olbia patients indicated sex as the only significant variable. 


\section{Discussion}

DM is associated with an increased risk of cardiovascular mortality, and, in this context, there are evidences highlighting the fact that diabetic women are at a higher risk than their male counterparts, particularly postmenopausal women [27]. While sex-gender differences in macrovascular complications are well established, less is known about microvascular complications in T2DM.

In our population, the prevalence of DR was $20.8 \%$, slightly lower than described in other sets [28-32]. Although our prevalence seems lower than described in other sets, we have to remember that in the other realities, diabetic operative units deal mainly with complicated T2DM patients, while in Sardinia, more than $95 \%$ of the diabetic population attend a diabetic operative unit. This data is also important to define a better epidemiologic DR rate among T2DM patients, which in our Sardinian population appears to be approximately $20.8 \%$.

Sex-gender differences in diabetes and in some diabetic complications are well defined, but in DR, these differences are less evident, due to the heterogeneity of the published studies in terms of ethnic origin of the population studied, number of patients analyzed, and selection bias. Male sex is generally, but not always, considered an independent risk factor for DR. Besides what has already been discussed in the introduction, several studies give controversial results on sex-gender differences in diabetic retinopathy. A large-scale study performed in the United States revealed that in diabetic patients over the age of 40 years, men show a $50 \%$ higher prevalence of diabetic retinopathy than women [17]. On the other hand, the LALES study [33] showed no statistically significant difference in the incidence of DR between the two sexes. Other studies have also shown this [1,34-37]. The UKPDS 50 study [38] also found no difference in prevalence between the two sexes $(p=0.67)$, with women showing a lower rate of progression of DR than men. In addition, data from a large clinical register in Denmark show no clear sex-gender differences in DR rate, but men have a higher risk for experiencing sight-threatening DR [39].

Male sex seems to be a risk factor for diabetes in adults as well as in juveniles, at least for western countries [40-42], while it is quite the opposite in countries where the population is of non-European origin, in which the prevalence of diabetes seems to be higher in women [43]. Among our patients, women represented $43 \%$ of the sample. In some studies that found male sex as a risk factor for DR, men also showed higher $\mathrm{HbA1c}$ levels and higher systolic and diastolic blood pressure values than women. Since these are risk factors for progression of DR [44], it could explain the sex-gender difference in the progression rate of DR found in men as an increased presence of additional risk factors for DR. The imbalanced distribution of risk factors among genders could be caused by differences in lifestyle [39], although sex hormones might have a role. DR often progresses during pregnancy, which is associated with higher estrogen and progesterone levels [45,46]. However, it has been demonstrated that women following a tight metabolic control regimen during pregnancy do not show an elevated risk for progression of DR, although the risk often increases again in the postpartum period, since this tight metabolic regimen frequently is no longer followed [45-47].

Mortality and disability after a first vascular event are higher in women, and there are evidences reporting that women receive less medical care regarding cardiovascular complications even in presence of diabetes, or, in any case, reach targets less frequently. From published studies, it appears clear that: (1) women come later and in worse clinical conditions to diagnosis of diabetes, (2) women are more obese at diagnosis and reach guideline target goals for glycated hemoglobin, LDL-cholesterol, or blood pressure control to a much lesser extent [48]; (3) women have a lesser chance of receiving all the diagnostic and therapeutic measures than diabetic men, even if it is well known that mortality after a first cardiovascular event is more elevated in diabetic women [49,50]; (4) finally, some antiaggregating and antihypertensive drugs seem to be less efficacious in diabetic WOMEN, while side effects of some hypoglycemic agents seem to be more frequent, reducing treatment compliance. In a recent ongoing prospective study, the side effects of metformin were shown to have the same incidence in men and women, but with the latter showing greater intensity and duration of these side effects, which affects compliance to drug treatment (preliminary personal observation). Studies focused on 
sex-gender differences in diabetic microvascular complications are indeed scarcely represented, both at the preclinical and clinical level, mainly due to the well-known limitations of inclusion criteria in trials, but also due to the difficulty of dissecting genetic and environment interactions. Certainly, the lack of capacity to directly target the mechanism initiating the disease, instead of the epiphenomenon, is the cause of the partial failure in the control of diabetic microvascular complication, and this is true in sex-gender oriented medicine as well. Neuroretinal dysfunction can be used to predict the location of future retinopathy up to three years before it manifests, and recently, in adult type 2 diabetic patients, an abnormal local neuroretinal function as been shown in men as compared to women [51]. If confirmed, this might be an alternative explanation for the higher prevalence of diabetic retinopathy in male subjects, in spite of the fact that women had more risk factors for diabetic retinopathy onset and progression.

In this large set of Sardinian T2DM patients, we show that women and men equally receive drug therapy for diabetes and associated pathologies (mainly hypertension and hypercholesterolemia), but women have greater prevalence of hypertension and chronic renal failure and show worse glycemic metabolic control, as is known in the literature [8,9]. The less satisfactory results of drug therapy obtained in women may be related to a different physiological response in the two sexes to the drugs (e.g., the statins), or a difference in adverse drug reactions that result in less compliance to the treatment.

RAAS modulators, mainly ACEI and ARB, may reduce onset and progression of DR in normotensive Type 1 diabetic patients [52,53], and these drugs are able to cause regression of mild DR in normoalbuminuric Type 2 diabetic patients [54]. A recent meta-analysis pointed out that RASS modulators (ACEI more than ARB) might indeed reduce onset and progression of DR in normotensive diabetic patients [55]. In the OT subset of patients, no difference in ACEI/ARB use was evident between men and women.

Finally, the role of sex hormones on retinal disorder must be considered. Recently, the subject has been reviewed [56]. It appears that estrogens, androgens, and progesterone receptors are present throughout the eye and that these steroids are locally produced in ocular tissues. The estrogenic cycle might have a beneficial effect on neuroretinal function, with estrogens, via a vasodilator effect on retinal perfusion, being protective, while testosterone and progesterone, via a vasocostrictive effect, might be a cause of progression. Although interesting, the effect of sex hormones on the retina and their contribution to retinal disorders remain to be proved.

A limitation of this study is that is not a longitudinal study able to detect, in a gender-oriented manner, who might have more rapid progression to DR. A longitudinal prospective study is starting now with these patients and hopefully in the next years we will clarify this aspect.

There are some strengths in this paper: (1) the big sample size of enrolled patients; (2) the multicenter design with the enrollment done in seven different operative units and the replication of the results in two different sets; (3) more than 98\% of T2DM patients in Sardinia refer to a diabetes operative unit, resulting in a clear picture of the real prevalence of retinopathy in T2DM patients; and (4) comprehensive data on potential confounders variables in $5362 \mathrm{~T} 2 \mathrm{DM}$ patients.

\section{Conclusions}

In conclusion, in our large sample of T2DM patients, women, although having the same drug treatment as men, showed worse glycemic metabolic control and higher prevalence of hypertension and chronic renal failure, all of which are well-established risk factors for DR, but men showed higher prevalence of DR of any grade, suggesting an independent sex-gender effect. Whether male sex is a cause of diabetic retinopathy development, or female sex is protective, remains to be proven.

Supplementary Materials: The following are available online at http://www.mdpi.com/2673-4540/1/1/1/s1, Figure S1: Flow chart of the study.

Author Contributions: S.C. and G.T. designed the research; A.G., M.A.S., P.C., G.M., M.A.F., D.P., R.M.P. and A.L. conducted the research; S.C., G.T. and I.C. analyzed the data, S.R. review of doubtful cases of diabetic retinopathy 
and S.C. wrote the manuscript. G.T. had primary responsibility for the final content. All authors read and approved the final manuscript.

Funding: This research received no external funding.

Acknowledgments: We thank Flavia Franconi for discussion and input given to the realization of this study. S.C. and G.T. are member of the scientific association JANASDIA.

Conflicts of Interest: The authors declare no conflict of interest.

\section{References}

1. Zhang, X.; Saaddine, J.B.; Chou, C.F.; Cotch, M.F.; Cheng, Y.J.; Geiss, L.S.; Gregg, E.W.; Albright, A.L.; Klein, B.E.K.; Klein, R. Prevalence of diabetic retinopathy in the United States, 2005-2008. JAMA 2010, 304, 649-656. [CrossRef] [PubMed]

2. Lachin, J.M.; White, N.H.; Hainsworth, D.P.; Sun, W.; Cleary, P.A.; Nathan, D.M. Effect of intensive diabetes therapy on the progression of diabetic retinopathy in patients with type 1 diabetes: 18 years of follow-up in the DCCT/EDIC. Diabetes 2015, 64, 631-642. [PubMed]

3. Schanzlin, D.J.; Jay, W.H.; Fritz, K.J.; Tripathi, R.C.; Gonen, B. Hemoglobin A1 and diabetic retinopathy. Am. J. Ophthalmol. 1979, 88, 1032-1038. [CrossRef]

4. Kaewput, W.; Thongprayoon, C.; Rangsin, R.; Ruangkanchanasetr, P.; Mao, M.A.; Cheungpasitporn, W. Associations of renal function with diabetic retinopathy and visual impairment in type 2 diabetes: A multicenter nationwide cross-sectional study. World J. Nephrol. 2019, 8, 33-43. [CrossRef] [PubMed]

5. Jenchitr, W.; Samaiporn, S.; Lertmeemongkolchai, P.; Chongwiriyanurak, T.; Anujaree, P.; Chayaboon, D.; Pohikamjorn, A. Prevalence of diabetic retinopathy in relation to duration of diabetes mellitus in community hospitals of Lampang. J. Med. Assoc. Thai 2004, 87, 1321-1326. [PubMed]

6. Associazione Medici Diabetologi and Società Italiana di Diabetologia (Ed.) Standard Italiani per la Cura del Diabete Mellito AMD-SID; Associazione Medici Diabetologi and Società Italiana di Diabetologia: Rome, Italy, 2016; Available online: http://www.siditalia.it/pdf/Standard\%20di\%20Cura\%20AMD\%20-\%20SID\%202018_ protetto.pdf (accessed on 27 April 2018).

7. Campesi, I.; Franconi, F.; Seghieri, G.; Meloni, M. Sex-gender-related therapeutic approaches for cardiovascular complications associated with diabetes. Pharm. Res. 2017, 119, 195-207. [CrossRef]

8. Franconi, F.; Campesi, I.; Occhioni, S.; Tonolo, G. Sex-gender differences in diabetes vascular complications and treatment. Endocr. Metab. Immune Disord. Drug Targets 2012, 12, 179-196. [CrossRef]

9. Seghieri, G.; Policardo, L.; Anichini, R.; Franconi, F.; Campesi, I.; Cherchi, S.; Tonolo, G. aThe Effect of Sex and Gender on Diabetic Complications. Curr. Diabetes Rev. 2016, 13, 148-160. [CrossRef]

10. Al-Rubeaan, K.; Abu El-Asrar, A.M.; Youssef, A.M.; Subhani, S.N.; Ahmad, N.A.; Al-Sharqawi, A.H.; Almutlaq, H.M.; David, S.K.; Alnaqeb, D. Diabetic retinopathy and its risk factors in a society with a type 2 diabetes epidemic: A Saudi National Diabetes Registry-based study. Acta Ophthalmol. 2015, 93, e140-e147. [CrossRef]

11. Pradeepa, R.; Anitha, B.; Mohan, V.; Ganesan, A.; Rema, M. Risk factors for diabetic retinopathy in a South Indian Type 2 diabetic population-the Chennai Urban Rural Epidemiology Study (CURES) Eye Study 4. Diabet Med. 2008, 25, 536-542. [CrossRef]

12. Rani, P.K.; Raman, R.; Chandrakantan, A.; Pal, S.S.; Perumal, G.M.; Sharma, T. Risk factors for diabetic retinopathy in self-reported rural population with diabetes. J. Postgrad. Med. 2009, 55, 92-96. [PubMed]

13. Kashani, A.H.; Zimmer-Galler, I.E.; Shah, S.M.; Dustin, L.; Do, D.V.; Eliott, D.; Haller, J.A.; Nguyen, Q.D. Retinal thickness analysis by race, gender, and age using Stratus OCT. Am. J. Ophthalmol. 2010, 149, 496-502 e1. [CrossRef]

14. Hammes, H.P.; Welp, R.; Kempe, H.P.; Wagner, C.; Siegel, E.; Holl, R.W. Risk Factors for Retinopathy and DME in Type 2 Diabetes-Results from the German/Austrian DPV Database. PLoS ONE 2015, 10, e0132492. [CrossRef] [PubMed]

15. Constable, I.J.; Knuiman, M.W.; Welborn, T.A.; Cooper, R.L.; Stanton, K.M.; McCann, V.J.; Grose, G.C. Assessing the risk of diabetic retinopathy. Am. J. Ophthalmol. 1984, 97, 53-61. [CrossRef]

16. West, K.M.; Ahuja, M.M.; Bennett, P.H.; Grab, B.; Grabauskas, V.; Mateo-de-Acosta, O.; Fuller, J.H.; Jarrett, R.J.; Keen, H.; Kosaka, K.; et al. Interrelationships of microangiopathy, plasma glucose and other risk factors in 3583 diabetic patients: A multinational study. Diabetologia 1982, 22, 412-420. [CrossRef] [PubMed] 
17. Deshpande, A.D.; Harris-Hayes, M.; Schootman, M. Epidemiology of diabetes and diabetes-related complications. Phys. Ther. 2008, 88, 1254-1264. [CrossRef] [PubMed]

18. Kajiwara, A.; Miyagawa, H.; Saruwatari, J.; Kita, A.; Sakata, M.; Kawata, Y.; Oniki, K.; Yoshida, A.; Jinnouchi, H.; Nakagawa, K. Gender differences in the incidence and progression of diabetic retinopathy among Japanese patients with type 2 diabetes mellitus: A clinic-based retrospective longitudinal study. Diabetes Res. Clin. Pr. 2014, 103, e7-e10. [CrossRef] [PubMed]

19. Pirart, J. Diabetes mellitus and its degenerative complications: A prospective study of 4,400 patients observed between 1947 and 1973 (author's transl). Diabete Metab 1977, 3, 97-107.

20. Jervell, J.; Moe, N.; Skjaeraasen, J.; Blystad, W.; Egge, K. Diabetes mellitus and pregnancy-management and results at Rikshospitalet, Oslo, 1970-1977. Diabetologia 1979, 16, 151-155. [CrossRef]

21. Moloney, J.B.; Drury, M.I. The effect of pregnancy on the natural course of diabetic retinopathy. Am. J. Ophthalmol. 1982, 93, 745-756. [CrossRef]

22. Solomon, S.D.; Chew, E.; Duh, E.J.; Sobrin, L.; Sun, J.K.; VanderBeek, B.L.; Wykoff, C.C.; Gardner, T.W. Diabetic retinopathy: A position statement by the American Diabetes Association. Diabetes Care 2017, 40, 412-418. [CrossRef] [PubMed]

23. Madendag, Y.; Acmaz, G.; Atas, M.; Sahin, E.; Tayyar, A.T.; Madendag, I.C.; Ozdemir, F.; Senol, V. The effect of oral contraceptive pills on the macula, the retinal nerve fiber layer, and choroidal thickness. Med. Sci. Monit. 2015, 23, 5657-5661. [CrossRef]

24. Marino, M.; Masella, R.; Bulzomi, P.; Campesi, I.; Malorni, W.; Franconi, F. Nutrition and human health from a sex-gender perspective. Mol. Asp. Med. 2011, 32, 1-70. [CrossRef] [PubMed]

25. Levey, A.S.; Stevens, L.A.; Schmid, C.H.; Zhang, Y.L.; Castro, A.F., 3rd; Feldman, H.I.; Kusek, J.W.; Eggers, P.W.; van Lente, F.; Greene, T.; et al. A new equation to estimate glomerular filtration rate. Ann. Intern. Med. 2009, 150, 604-612. [CrossRef]

26. Ellis, D.; Burgess, P.I.; Kayange, P. Management of diabetic retinopathy. Malawi Med. J. 2013, 25, 116-120.

27. $\mathrm{Hu}, \mathrm{G}$. Gender difference in all-cause and cardiovascular mortality related to hyperglycaemia and newly-diagnosed diabetes. Diabetologia 2003, 46, 608-617. [CrossRef] [PubMed]

28. Yau, J.W.; Rogers, S.L.; Kawasaki, R.; Lamoureux, E.L.; Kowalski, J.W.; Bek, T.; Chen, S.; Dekker, J.M.; Fletcher, A.E.; Grauslund, J.; et al. Global prevalence and major risk factors of diabetic retinopathy. Diabetes Care 2012, 35, 556-564. [CrossRef]

29. Disoteo, O.; Grimaldi, F.; Papini, E.; Attanasio, R.; Tonutti, L.; Pellegrini, M.A.; Guglielmi, R.; Borretta, G. State-of-the-Art Review on Diabetes Care in Italy. Ann. Glob. Health 2015, 81, 803-813. [CrossRef]

30. Segato, T.; Midena, E.; Grigoletto, F.; Zucchetto, M.; Fedele, D.; Piermarocchi, S.; Crepaldi, G. The epidemiology and prevalence of diabetic retinopathy in the Veneto region of north east Italy. Veneto Group for Diabetic Retinopathy. Diabetes Med. 1991, 8, S11-S16. [CrossRef]

31. Porta, M.; Taulaigo, A.V. The changing role of the endocrinologist in the care of patients with diabetic retinopathy. Endocrine 2014, 46, 199-208. [CrossRef]

32. Cruciani, F.; Abdolrahimzadeh, S.; Vicari, A.; Amore, F.M.; Di Pillo, S.; Mazzeo, L. Causes of blind certification in an Italian province and comparison with other European countries. Clin. Ter. 2010, 161, e11-e16.

33. Mazhar, K.; Varma, R.; Choudhury, F.; McKean-Cowdin, R.; Shtir, C.J.; Azen, S.P. Severity of diabetic retinopathy and health-related quality of life: The Los Angeles Latino Eye Study. Ophthalmology 2011, 118, 649-655. [CrossRef]

34. De Block, C.E.; De Leeuw, I.H.; Van Gaal, L.F. Impact of overweight on chronic microvascular complications in type 1 diabetic patients. Diabetes Care 2005, 28, 1649-1655. [CrossRef]

35. Kostev, K.; Rathmann, W. Diabetic retinopathy at diagnosis of type 2 diabetes in the UK: A database analysis. Diabetologia 2013, 56, 109-111. [CrossRef]

36. Hammes, H.P.; Kerner, W.; Hofer, S.; Kordonouri, O.; Raile, K.; Holl, R.W. Diabetic retinopathy in type 1 diabetes-a contemporary analysis of 8,784 patients. Diabetologia 2011, 54, 1977-1984. [CrossRef]

37. Raman, R.; Rani, P.K.; Reddi Rachepalle, S.; Gnanamoorthy, P.; Uthra, S.; Kumaramanickavel, G.; Sharma, T. Prevalence of diabetic retinopathy in India: Sankara Nethralaya Diabetic Retinopathy Epidemiology and Molecular Genetics Study report 2. Ophthalmology 2009, 116, 311-318. [CrossRef]

38. Stratton, I.M.; Kohner, E.M.; Aldington, S.J.; Turner, R.C.; Holman, R.R.; Manley, S.E.; Matthews, D.R. UKPDS 50: Risk factors for incidence and progression of retinopathy in Type II diabetes over 6 years from diagnosis. Diabetologia 2001, 44, 156-163. [CrossRef] 
39. Mehlsen, J.; Erlandsen, M.; Poulsen, P.L.; Bek, T. Identification of independent risk factors for the development of diabetic retinopathy requiring treatment. Acta Ophthalmol. 2011, 89, 515-521. [CrossRef]

40. Kaiser, A.; Vollenweider, P.; Waeber, G.; Marques-Vidal, P. Prevalence, awareness and treatment of type 2 diabetes mellitus in Switzerland: The CoLaus study. Diabet. Med. 2012, 29, 190-197. [CrossRef]

41. Maahs, D.M.; West, N.A.; Lawrence, J.M.; Mayer-Davis, E.J. Epidemiology of type 1 diabetes. Endocrinol. Metab. Clin. N. Am. 2010, 39, 481-497. [CrossRef]

42. Awa, W.L.; Fach, E.; Krakow, D.; Welp, R.; Kunder, J.; Voll, A.; Zeyfang, A.; Wagner, C.; Schütt, M.; Boehm, B.; et al. Type 2 diabetes from pediatric to geriatric age: Analysis of gender and obesity among 120,183 patients from the German/Austrian DPV database. Eur. J. Endocrinol. 2012, 167, 245-254. [CrossRef]

43. Cunningham-Myrie, C.; Younger-Coleman, N.; Tulloch-Reid, M.; McFarlane, S.; Francis, D.; Ferguson, T.; Gordonstrachan, G.; Wilks, R. Diabetes mellitus in Jamaica: Sex differences in burden, risk factors, awareness, treatment and control in a developing country. Trop. Med. Int. Health 2013, 18, 1365-1378. [CrossRef]

44. Matthews, D.R.; Stratton, I.M.; Aldington, S.J.; Holman, R.R.; Kohner, E.M. Risks of progression of retinopathy and vision loss related to tight blood pressure control in type 2 diabetes mellitus: UKPDS 69. Arch. Ophthalmol. 2004, 122, 1631-1640.

45. Errera, M.H.; Kohly, R.P.; da Cruz, L. Pregnancy-associated retinal diseases and their management. Surv. Ophthalmol. 2013, 58, 127-142. [CrossRef]

46. Negrato, C.A.; Mattar, R.; Gomes, M.B. Adverse pregnancy outcomes in women with diabetes. Diabetol. Metab. Syndr. 2012, 4, 41. [CrossRef]

47. Lauszus, F.; Klebe, J.G.; Bek, T. Diabetic retinopathy in pregnancy during tight metabolic control. Acta Obs. Gynecol. Scand. 2000, 79, 367-370. [CrossRef]

48. Rossi, M.C.; Cristofaro, M.R.; Gentile, S.; Lucisano, G.; Manicardi, V.; Mulas, M.F.; Napoli, A.; Nicolucci, A.; Pellegrini, F.; Suraci, C.; et al. Sex disparities in the quality of diabetes care: Biological and cultural factors may play a different role for different outcomes: A cross-sectional observational study from the AMD Annals initiative. Diabetes Care 2013, 36, 3162-3168. [CrossRef]

49. Policardo, L.; Seghieri, G.; Francesconi, P.; Anichini, R.; Franconi, F.; Seghieri, C.; del Prato, S. Gender difference in diabetes-associated risk of first-ever and recurrent ischemic stroke. J. Diabetes Complicat. 2015, 29, 713-717. [CrossRef]

50. Barrett-Connor, E.; Ferrara, A. Isolated postchallenge hyperglycemia and the risk of fatal cardiovascular disease in older women and men. The Rancho Bernardo Study. Diabetes Care 1998, 21, 1236-1239. [CrossRef]

51. Ozawa, G.Y.; Bearse, M.A., Jr.; Adams, A.J. Male-female differences in diabetic retinopathy? Curr. Eye Res. 2015, 40, 234-246. [CrossRef]

52. Chaturvedi, N.; Porta, M.; Klein, R.; Orchard, T.; Fuller, J.; Parving, H.H.; Bilous, R.; Sjolie, A.K. Effect of candesartan on prevention (DIRECT-Prevent 1 ) and progression (DIRECT-Protect 1 ) of retinopathy in type 1 diabetes: Randomised, placebo-controlled trials. Lancet 2008, 372, 1394-1402. [CrossRef]

53. Mauer, M.; Zinman, B.; Gardiner, R.; Suissa, S.; Sinaiko, A.; Strand, T.; Drummond, K.; Donnelly, S.; Goodyer, P.; Gubler, M.C.; et al. Renal and retinal effects of enalapril and losartan in type 1 diabetes. N. Engl. J. Med. 2009, 361, 40-51. [CrossRef] [PubMed]

54. Sjolie, A.K.; Klein, R.; Porta, M.; Orchard, T.; Fuller, J.; Parving, H.H.; Bilous, R.; Chaturvedi, N. Effect of candesartan on progression and regression of retinopathy in type 2 diabetes (DIRECT-Protect 2): A randomised placebo-controlled trial. Lancet 2008, 372, 1385-1393. [CrossRef]

55. Wang, B.; Wang, F.; Zhang, Y.; Zhao, S.H.; Zhao, W.J.; Yan, S.L.; Wang, Y. Effects of RAS inhibitors on diabetic retinopathy: A systematic review and meta-analysis. Lancet Diabetes Endocrinol. 2015, 3, 263-274. [CrossRef]

56. Nuzzi, R.; Scalabrin, S.; Becco, A.; Panzica, G. Gonadal Hormones and Retinal Disorders: A Review. Front. Endocrinol. 2018, 9, 66. [CrossRef]

Publisher's Note: MDPI stays neutral with regard to jurisdictional claims in published maps and institutional affiliations. 